\title{
A Study to Compare the Effectiveness of Treadmill and Cross Trainer on Rate Pressure Product and Rate of Perceived Exertion in Hypertensive Patients
}

\author{
Shivani Sutaria ${ }^{1}$, Sweety Shah $^{2}$ \\ ${ }^{1}$ Post-Graduate student, SBB College of Physiotherapy, VSGH Hospital, Ahmedabad, India \\ ${ }^{2} \mathrm{Ph} . \mathrm{D}, \mathrm{MPT}$, SBB College of Physiotherapy, VSGH Hospital, Ahmedabad, India
}

Corresponding Author: Shivani Sutaria

\begin{abstract}
Background: Several cardiovascular events are to be related with the decrease in the myocardial oxygen supply when the demand increases. The valuable marker of cardiac function is Rate pressure product. It is the product of heart rate and systolic blood pressure. Hypertension has been identified as independent risk factors for adverse cardiovascular events.

Objective: The objective of the study was to determine the effect of treadmill and cross trainer on rate pressure product and rate of perceived exertion in hypertensive patients.

Method: An observational study was done on 32 hypertensive subjects with the age group between 35-60 years as per inclusion and exclusion criteria. The subject was divided into two groups. Group A was made to walk randomly on treadmill for $15 \mathrm{~min}$ and group B was made to exercise on cross trainer for 15 minutes. Before and after the completion of test, rate pressure product and rate of perceived exertion was measured.

Result: Non parametric test were used to compare outcomes before and after interventions within and between the groups. Result shows that there was significant improvement in rate pressure product $(\mathrm{p}<0.03)$ and rate of perceived exertion after walking on treadmill and exercising on cross trainer, while no significances noted while comparing between groups $(\mathrm{p}>0.88)$.

Conclusion: The present study concluded that both treadmill and cross trainer can be used effectively for exercise prescription and preventing cardiovascular risk in hypertensive patients, but the treadmill was prone to be more effective as the mean difference was low compared to cross trainer and there was greater muscle fatigue noted with cross trainer.
\end{abstract}

Key words: rate pressure product, rate of perceived exertion, treadmill, cross trainer, hypertension.

\section{INTRODUCTION}

Hypertension is defined as systolic blood pressure above $140 \mathrm{mmHg}$ and diastolic blood pressure above $90 \mathrm{mmHg}$. Blood pressure that fluctuates between hypertensive and normal values is termed as Labile HTN. ${ }^{[1]}$ Hypertension is the independent risk factors for various cardiovascular events such as hemorrhage, stroke, myocardial infarction and infraction of other organs as the high blood pressure leads to atherosclerosis due to accumulation of fat, cholesterol and other substance. ${ }^{[2]}$
There is increase in risk of cardiovascular mortality and morbidity with increase in sympathetic activation in essential hypertension. ${ }^{[3]}$

Myocardial oxygen demand can be determine by the various physiological measures such as heart rate, left ventricular preload and myocardial contractility. ${ }^{[4]}$ For monitoring individual exercise tolerance, RPE can be a valuable indicator. Borg Rate of Perceived Exertion was used in this study. ${ }^{[5]}$ Rate pressure product also referred as double product was found to be single 
most valuable measure to estimate myocardial oxygen consumption during rest and after exercise. Rate pressure product (RPP) is the product of heart rate and systolic blood pressure that is maximum pressure exerted by the blood on the vessel walls. RPP 25,000mmg .beats/min or higher than that was found to be normal exercise response. ${ }^{[6]}$ Rate pressure product is elevated during static or dynamic resistance or upper body work indicating increased myocardial oxygen demand. ${ }^{[7]}$ However the response of rate pressure product with treadmill and cross trainer was not found yet so the need of the study is to determine the appropriate exercise prescription and prevention of cardiovascular risk in hypertensive patients in terms of rate pressure product and rate of perceived exertion. So the aim of the study is to determine the effect of treadmill and cross trainer on rate pressure product and rate of perceived exertion on hypertensive patients.

\section{MATERIALS AND METHODOLOGY}

An observational study was conducted on 32 subjects ( 22 male and 10 female) with hypertension aged 35- 60 years using random sampling. Participants with neurological and musculoskeletal conditions were excluded. Materials used in the study were treadmill, cross trainer and sphygmomanometer. Participants were divided into group A and group B.
Group A was made to walk randomly on treadmill for 15 minutes and group B was made to exercise on cross trainer for 15 minute. Before commencing the exercise session Rate Pressure Product (RPP) and Rate of Perceived Exertion (RPE) as an outcome measure was taken in each exercise session and after completion of session same measurement was repeated.

Rate pressure product was calculated as per formula:

Rate pressure product $=$ heart rate $($ b.min-1) $\times$ systolic blood pressure (mm.Hg) $\div \mathbf{1 0 0 0}$

Rate of perceived exertion was measured using Borg rate of perceived exertion scale.

Statistical analysis: As the data was not normally distributed non parametric test was used. Wilcoxon test was used for comparing pre and post values within the group and Mann-Whitney was used to compare both groups using SPSS version 20.0. Significance level was fixed at $\mathrm{p}<0.05$.

\section{RESULT}

A total 32 subjects were included in study with mean age of 35- 60 years. There was significant improvement in rate pressure product and rate of perceived exertion after walking on treadmill and exercise on cross trainer within the group while no significance noted by comparing between group.

TABLE 1: EFFECT OF TREADMILL ON SBP, HR, RPP AND RPE IN GROUP A

\begin{tabular}{|l|l|l|l|l|l|}
\hline GROUP & VARIABLE & $\begin{array}{l}\text { PRE } \\
\text { MEAN } \pm \text { SD }\end{array}$ & $\begin{array}{l}\text { POST } \\
\text { MEAN } \pm \text { SD }\end{array}$ & P VALUE & SIGNIFICANCE \\
\hline & SBP & $1.30 \pm 2.28$ & $1.34 \pm 3.04$ & 0.003 & SIGNIFICANT \\
\hline A & HR & $72.9 \pm 6.99$ & $78.3 \pm 7.04$ & 0.003 & SIGNIFICANT \\
\hline & RPP & $9.54 \pm 1.05$ & $10.56 \pm 1.16$ & 0.003 & SIGNIFICANT \\
\hline & RPE & $6.0 \pm 0.00$ & $8.20 \pm 1.03$ & 0.003 & SIGNIFICANT \\
\hline
\end{tabular}

TABLE 2: EFFECT OF CROSS TRAINER ON SBP, HR, RPP AND RPE

\begin{tabular}{|l|l|l|l|l|l|}
\hline GROUP & VARIABLE & $\begin{array}{l}\text { PRE } \\
\text { MEAN } \pm \text { SD }\end{array}$ & $\begin{array}{l}\text { POST } \\
\text { MEAN } \pm \text { SD }\end{array}$ & P VALUE & SIGNIFICANCE \\
\hline & SBP & $1.31 \pm 4.67$ & $1.38 \pm 5.31$ & 0.05 & SIGNIFICANCE \\
\hline B & RR & $73.81 \pm 3.34$ & $80.1 \pm 4.04$ & 0.03 & SIGNIFICANCE \\
\hline & RPP & $9.69 \pm 0.55$ & $11.07 \pm 0.78$ & 0.03 & SIGNIFICANCE \\
\hline & RPE & $6.00 \pm 0.00$ & $9.54 \pm 129$ & 0.003 & SIGNIFICANCE \\
\hline
\end{tabular}

TABLE 3: COMPARING GROUP A AND GROUP

\begin{tabular}{|l|l|l|}
\hline VARIABLE & P VALUE & SIGNIFICANCE \\
\hline RPP & 0.88 & NOT SIGNIFICANCE \\
\hline RPE & 0.02 & SIGNIFICANCE \\
\hline
\end{tabular}

\section{DISCUSSION}

The present study was conducted to see the effects of blood pressure and heart 
rate response (RPP) during treadmill and cross training exercise. There were no adverse events found. Result shows that both treadmill and cross trainer was effective for exercise prescription and preventing cardiovascular risk in hypertensive patients. But the mean difference of cross trainer was found to be more $(1.4175 \pm 0.618)$ compared to treadmill $(0.959 \pm 0.451)$. Rate pressure product was higher in cross trainer compared to treadmill so myocardial oxygen consumption was high in cross trainer at RPE of 9-11 Borg rate of perceived exertion, for 15 minute duration in hypertensive subjects. So at a given exertion hypertensive patients should be allocated to treadmill as exercise induced myocardial oxygen consumption is significantly low. ${ }^{[8]}$

There is a greater cardiovascular strain during upper body and lower body training as the work requirement of myocardium increases considerably from the exacerbated rise in blood pressure thus produces higher rate pressure product in cross trainer ${ }^{[9]}$ Also the RPE was found to be significantly increase during both treadmill and cross trainer as the exercise intensity increases the heart rate increases thus RPE also increases in linearly fashion.

Brown, G.A., et al did a study on 18 untrained college student who perform treadmill and elliptical machine for 15 minute and concluded that there was no difference in calorie expenditure between treadmill and elliptical trainer at same RPE. However they found that during elliptical training HR was increase to $16-18$ beats/min because as compared to legs arm contribute more work. ${ }^{[10]}$

Heloisa G. Machado-Vidotti did a study on 10 healthy volunteer to determine the cardiac autonomic responses during upper versus lower limb discontinuous resistance exercise (RE) at different loads. Subject underwent the one-repetition maximum (1RM) test to determine the maximum load for the bench press and the leg press. And shows that during upper limb exercise training there was increase in the sympathetic activity with decrease in the vagal tone as compared to lower limb exercise. $^{[11]}$

Another study in 2002 on 12 CAD patients was conducted to see the cardiopulmonary response of elliptical cross training versus treadmill walking and shows that the there was greater cardiopulmonary response with elliptical training compared to treadmill training. ${ }^{[12]}$ Thus the present study concluded that both treadmill and cross trainer can be effective for prescribing exercise and reduces the cardiovascular risk but treadmill was found more effective compared to cross trainer.

Limitation of the study was sample size was small, specific protocol was not used to determine better accuracy of result. Future studies concerning different stages of hypertension can be done. Different age group can also be considered to know response differences in determining rate pressure product. Other outcome measures like heart rate recovery can be taken to predict cardiovascular risk or mortality.

Clinical implication of the study is that treadmill training should be used in hypertensive individuals because it does not involve use of upper extremity which does not increase workload on heart. So it is safe and beneficial for them. Hence treadmill training should be considered as a part of ADL activity in hypertensive individual.

\section{CONCLUSION}

There was significant change in RPP \& RPE in both the groups. Treadmill and Cross-trainer both can be used for exercise prescription to reduce cardiovascular risk in patients with hypertension, but the treadmill was prone to be more effective as the mean difference was low compared to cross trainer and also there was greater muscle fatigue noted with cross trainer.

\section{ACKNOWLEDGEMENTS}

Special thanks to all the subjects who participated in the study to make this study successful. I want to thank my parents and colleagues for motivation and their help 
throughout my study. I am thankful to my guide Dr. Sweety Shah for always supporting and motivating me throughout my study. I also want to thank all staff members of SBB College of Physiotherapy for their support without them, this study could not have been possible.

\section{Conflict of Interest: None}

\section{Source of Funding: None}

\section{Ethical Approval: Approved}

\section{REFERENCES}

1. Ellin Hillgass: Essentials of Cardiopulmonary Physical Therapy. Third edition.

2. Elizabet donna. Principles and practice of cardiopulmonary physical therapy. Third edition.

3. L Sikiru ${ }^{1}$ and GC Okoye ${ }^{2}$ Effect of interval training programme on pulse pressure in the management of hypertension: a randomized controlled trial. African health science. 2013 Sep; 13(3): 571-578.

4. Franz IW. Blood pressure response to exercise in normotensives and hypertensives. Canadian Journal of Sport Science. 1991;16(4):296-301.

5. Wolters Kluwer. ACSM'S Guidelines for Exercise Testing and Prescription. $10^{\text {th }}$ edition.

6. Wolters Kluwer. ACSM'S Guidelines for Exercise Testing and Prescription. $7^{\text {th }}$ edition.
7. W.larry Kenney, Jcak H> Wilmore, David L.Costil. Physiology of sport and exercise. Fifth edition, page no. 190.

8. Brown GA, Cook CM, Krueger RD, Heelan KA.Comparison of energy expenditure on a treadmill vs. an elliptical device at a selfselected exercise intensity. Strength Cond Res. 2010 Jun:24(6): 1643-9, doi; 10:1519/JSC.

9. Baird Fort Hays State University. Effects Of Upper Body vs Lower Body Training On Rate-Pressure Product. Summer 2012.

10. Brown, G.A., Cook, C.M., Krueger, R.D., \& Heelan, K.A.Comparison of energy expenditure on a treadmill vs. an elliptical device at a self-selected exercise intensity.(2010). Journal of Strength and Conditioning Research, 24(6), 1643-49

11. Heloisa G. Machado-Vidotti1. Cardiac autonomic response during upper versus lower limb resistance training in healthy elderly man. raz J Phys Ther. 2014 Jan-Feb; 18(1): $\quad 9-18$. doi: $10.1590 /$ S141335552012005000140.

12. Buckley JP, Davis JA, Simpson T. Cardiorespiratory responses to rowing ergometry and treadmill exercise soon after myocardial infarction. Med Sci Sports Exerc 1999;31:1721-6.

How to cite this article: Sutaria S, Shah S. A study to compare the effectiveness of treadmill and cross trainer on rate pressure product and rate of perceived exertion in hypertensive patients. Int J Health Sci Res.2021;11(5):58-61. DOI: https://doi.org/10.52403/ijhsr.20210508 